\title{
An Integrated Epigenome and Transcriptome Analysis to Clarify the Effect of Epigenetic Inhibitors on GIST
}

\author{
TAKESHI NIINUMA ${ }^{1}$, HIROSHI KITAJIMA $^{1}$, EIICHIRO YAMAMOTO ${ }^{1,2}$, REO MARUYAMA $^{3}$, \\ HIRONORI AOKI ${ }^{1}$, TAKU HARADA ${ }^{1}$, KAZUYA ISHIGURO ${ }^{1}$, GOTA SUDO ${ }^{1}$, MUTSUMI TOYOTA ${ }^{1}$, \\ AYANO YOSHIDO $^{1}$, MASAHIRO KAI ${ }^{1}$, HIROSHI NAKASE ${ }^{2}$, TAMOTSU SUGAI ${ }^{4}$ and HIROMU SUZUKI ${ }^{1}$ \\ ${ }^{1}$ Department of Molecular Biology, Sapporo Medical University School of Medicine, Sapporo, Japan; \\ ${ }^{2}$ Department of Gastroenterology and Hepatology, Sapporo Medical University School of Medicine, Sapporo, Japan; \\ ${ }^{3}$ Project for Cancer Epigenomics, Cancer Institute, Japanese Foundation for Cancer Research, Tokyo, Japan; \\ ${ }^{4}$ Department of Molecular Diagnostic Pathology, Iwate Medical University, Morioka, Japan
}

\begin{abstract}
Background/Aim: Epigenetic alterations play an important role in the pathogenesis of gastrointestinal stromal tumors (GISTS). To obtain further insight into the GIST epigenome, we analyzed genome-wide histone modification and DNA methylation in GIST cells. Materials and Methods: To reverse epigenetic silencing, GIST-T1 cells were treated with a DNA methyltransferase inhibitor and a histone deacetylase inhibitor, and subsequently H3K4me3 levels, the DNA methylome, and the transcriptome were analyzed. Results: Treatment with epigenetic inhibitors not only up-regulated genes with DNA methylation, but also genes related to interferon signaling. ChIP-seq analysis revealed that drug treatment upregulated $\mathrm{H} 3 \mathrm{~K} 4 \mathrm{me} 3$ levels in retrotransposons, including endogenous retroviruses (ERV). Finally, utilizing the omics data, we found that hypermethylation of MEG3 is a frequent event and an indicator of poorer prognosis in GIST patients. Conclusion: Epigenetic inhibitors may activate interferon signaling via viral mimicry in GIST cells. Moreover, epigenome data could be a useful resource to identify novel GIST-related genes.
\end{abstract}

Gastrointestinal stromal tumors (GISTs) are the most frequently occurring gastrointestinal mesenchymal tumors and are derived from interstitial cells of Cajal (ICCs), which function as pacemaker cells within the gastrointestinal tract (1). The majority of GISTs ( $\sim 90 \%)$ harbor constitutively activating KIT mutations, while a subset exhibit PDGFRA mutations. The resulting

This article is freely accessible online.

Correspondence to: Hiromu Suzuki, MD, Ph.D., Department of Molecular Biology, Sapporo Medical University School of Medicine, S1, W17, Chuo-ku, Sapporo 060-8556, Japan. Tel: +81 116112111, Fax: +81 116221918, e-mail: hsuzuki@sapmed.ac.jp

Key Words: GIST, lncRNA, epigenetics. aberrant tyrosine kinase receptor activation is exceedingly important for GIST tumorigenesis. In addition to genetic abnormalities, recent evidence strongly suggests the importance of epigenetic alterations in the pathogenesis of GISTs. For example, a deficiency in succinate dehydrogenase (SDH), a mitochondrial enzyme associated with energy production, is causally associated with aberrant DNA hypermethylation in pediatric GISTs (2). Moreover, it was recently shown that DNA methylation induced by SDH deficiency inhibits normal CCCTC-Binding Factor (CTCF) binding within GIST cells, which leads to changes in chromosomal topology and activation of oncogenes through aberrant superenhancer activity (3). DNA methylation also plays pivotal roles in adult GISTs. For instance, advanced GISTs exhibit a larger number of methylated genes than small GISTs, and hypermethylation of a subset of genes is associated with a poorer prognosis in GIST patients (4). In addition, we previously showed that genome-wide hypomethylation of long interspersed nuclear element-1 (LINE1) is associated with chromosomal aberrations and malignancy in GISTs and that hypermethylation of $\mathrm{CpG}$ islands is associated with transcriptional silencing of microRNA (miRNA) genes in GIST cells $(5,6)$.

Epigenetic regulation of gene expression is also strongly associated with histone modifications (7). In an earlier study, we demonstrated that a combination of a DNA methyltransferase inhibitor, 5-aza-2'-deoxycytidine (5-aza$\mathrm{dC})$, and a histone deacetylase inhibitor, 4-phenylbutyric acid (4-PBA), effectively restored expression of epigenetically silenced miRNA genes in GIST cells (5). Histone methylation also plays pivotal roles in transcriptional regulation, and its alteration is deeply involved in tumorigenesis. For instance, trimethylation of histone H3 lysine 4 (H3K4me3) is a marker of active transcription, while $\mathrm{H} 3 \mathrm{~K} 27 \mathrm{me} 3$ is associated with gene silencing (8). We previously showed that an oncogenic long noncoding RNA (lncRNA), HOTAIR, is frequently up-regulated in GISTs 
Table I. Sequences of the primers used in this study.

\begin{tabular}{lll}
\hline MEG3 bisulfite pyroseq & 5'-GAGAAATGAGYGTATTGTAGTAGAA-3' & 5'-Bio-AACCRCCRCCAAAACCAACRAACCA-3' \\
Sequencing primer & 5'-ATTTAGTTAG bp \\
Sequence to analyze & 5'-CGTAGACGGCG-3' & \\
MEG3 bisulfite seq & 5'-GAGTAATTTGTTATAGAATTTGGGGGG-3' & 5' 'CAAAACCCAAAATCAAACAAACTC-3' \\
\hline
\end{tabular}

$\mathrm{Y}=\mathrm{C}$ or $\mathrm{T} ; \mathrm{R}=\mathrm{A}$ or $\mathrm{G}$; Bio: biotin.

exhibiting aggressive behavior and that the gene's activation is associated with elevated levels of H3K4me3 (9).

In the present study, we sought to extend our knowledge of the epigenome of GIST cells by analyzing their genomewide DNA methylation and $\mathrm{H} 3 \mathrm{~K} 4 \mathrm{me} 3$ states and performing an integrative analysis using epigenome and transcriptome data. We also tested the effect of epigenetic drugs, including DNMT and HDAC inhibitors, in GIST cells. Our findings indicate that epigenome and transcriptome data are useful resources for identifying novel GIST-related genes and that restoration of epigenetic silencing can activate interferon signaling in GIST cells.

\section{Materials and Methods}

Cell line and tissue samples. GIST-T1 cells were obtained and cultured as described previously (10). Cells were treated with $2 \mu \mathrm{M}$ 5-aza-dC (Sigma-Aldrich, St. Louis, MO, USA) for $72 \mathrm{~h}$ and then treated with or without $3 \mathrm{mM}$ 4-phenylbutyric acid (4-PBA; SigmaAldrich) for an additional $48 \mathrm{~h}$, replacing the drug and medium every $24 \mathrm{~h}$. A total of 44 primary GIST specimens were obtained as described previously (9). Informed consent was obtained from all patients before collection of the specimens, and this study was approved by the institutional review board. Risk grades were assessed according to the risk classification system proposed by Fletcher et al. based on tumor size and mitotic activity (11). Total RNA was extracted using TRI Reagent (COSMO BIO, Tokyo, Japan), and genomic DNA was extracted using the standard phenolchloroform procedure.

Gene expression microarray analysis. Gene expression microarray analysis was carried out according to the manufacturer's instructions (Agilent Technologies, Santa Clara, CA, USA). Briefly, $100 \mathrm{ng}$ of total RNA were amplified and labeled using a Low-input Quick Amp Labelling kit One-color (Agilent Technologies), after which the synthesized cRNA was hybridized to a SurePrint G3 Human GE microarray v2 (G4851; Agilent Technologies). The microarray data were analyzed using GeneSpring GX version 13 (Agilent Technologies). The Gene Expression Omnibus accession number for the microarray data is GSE171499.

Chromatin immunoprecipitation-sequencing. Chromatin immunoprecipitation-sequencing (ChIP-seq) of $\mathrm{H} 3 \mathrm{~K} 4 \mathrm{me} 3$ was performed as described previously (12). Sequencing data were mapped to human genome GRCh38 using bowtie2 version 2.4.2. Peaks were identified using Model-based Analysis for ChIP-seq 2 (MACS2) software version 2.2.7.1 (13) and were annotated using ChIPpeakAnno version
3.12 (14) and HOMER version 4.11. ChIP-seq results were visualized using deeptools version 3.5.0 and Integrative Genomics Viewer version 2.8 .13 (15). The Gene Expression Omnibus accession number for the ChIP-seq results is GSE171499.

Infinium assay. The DNA methylome in GIST-T1 cells was analyzed using an Infinium HumanMethylation450 BeadChip according to the manufacturer's instructions (Illumina, San Diego, CA, USA), as described previously (16). Data were analyzed using $\mathrm{R}$ version 4.0.3 and RStudio version 1.4. The Gene Expression Omnibus accession number for the Infinium assay data is GSE171499. In addition, BeadChip data obtained from 44 primary GISTs without SDH mutation (GSE34387) were also used for analysis (2).

DNA methylation analysis. Bisulfite pyrosequencing analysis was performed as described previously (12). For bisulfite sequencing, amplified PCR products were cloned into pCR2.1-TOPO vector (Thermo Fisher Scientific, Waltham, MA, USA), after which 10 clones were sequenced using an ABI3130x automated sequencer (Thermo Fisher Scientific). Sequence information for the primers is listed in Table I.

Statistical analysis. Quantitative variables were analyzed using Student's $t$-test or one-way analysis of variance (ANOVA). Categorical values were compared using Fisher's exact test. Survival was analyzed using the Kaplan-Meier method; survival curves were compared using the log-rank test for two-group comparison. All data were analyzed using EZR version 1.32 (17).

\section{Results}

Overview of histone and DNA methylation in GIST cells. The workflow for the present study is shown in Figure 1A. Transcriptome data from GIST-T1 cells were obtained through microarray analysis. Genome-wide patterns of histone $\mathrm{H} 3 \mathrm{~K} 4 \mathrm{me} 3$, a marker of active transcription, were analyzed using ChIP-seq. Among a total of 23462 H3K4me3 peaks detected with ChIP-seq, the majority (62.7\%) were located within gene promoter regions (Figure 1B). To assess the association between gene expression and histone modification, we categorized the genes into three groups according to their microarray signal intensities: genes with low expression ( 0 to $25^{\text {th }}$ percentile), intermediate expression $\left(25^{\text {th }}\right.$ to $75^{\text {th }}$ percentile), and high expression $\left(75^{\text {th }}\right.$ to 100 th percentile). We then assessed the enrichment of $\mathrm{H} 3 \mathrm{~K} 4 \mathrm{me} 3$ at the transcription start sites (TSSs) of the genes in the 
A

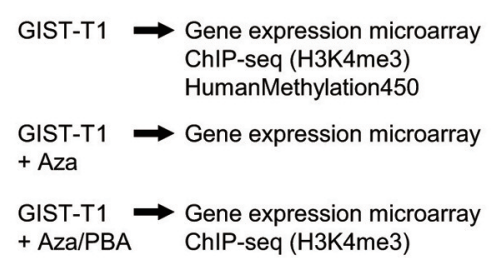

B

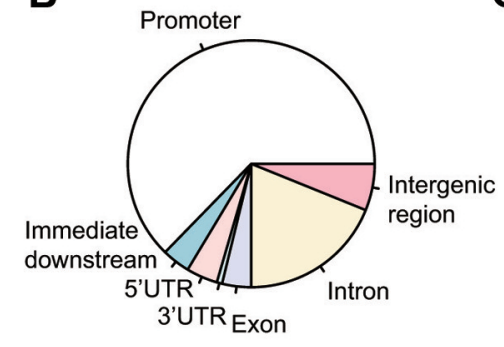

C

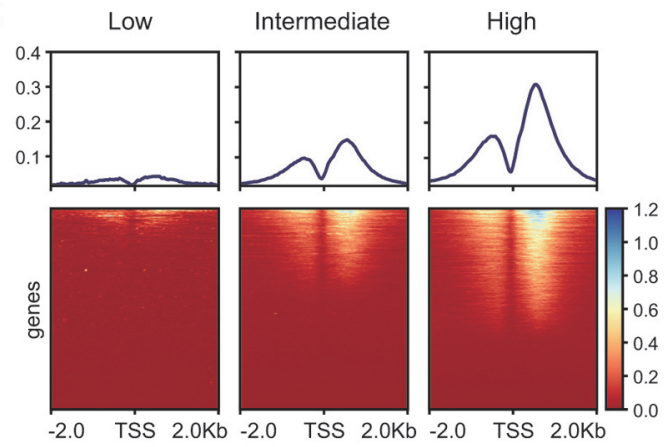

D

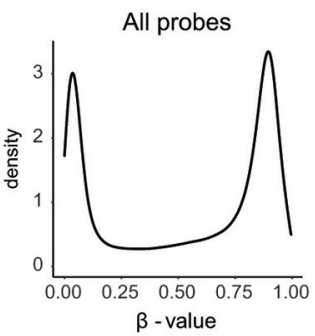

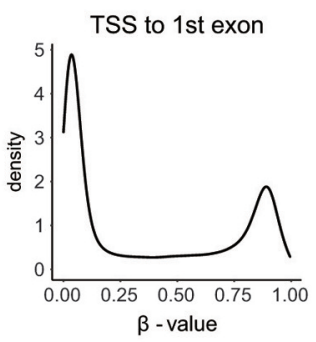
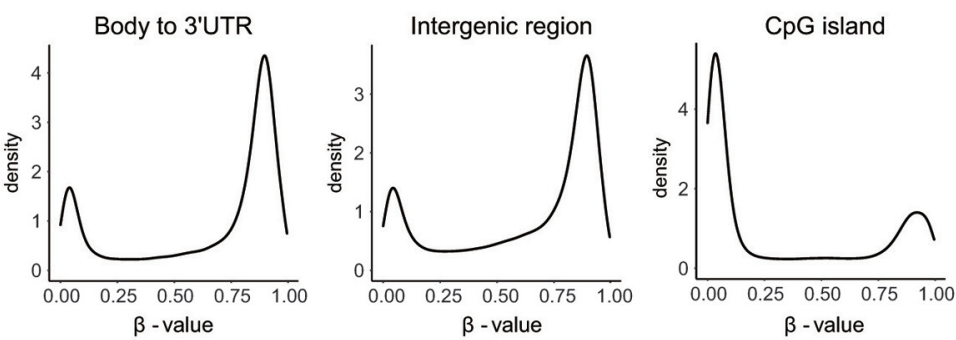

$\mathbf{E}$
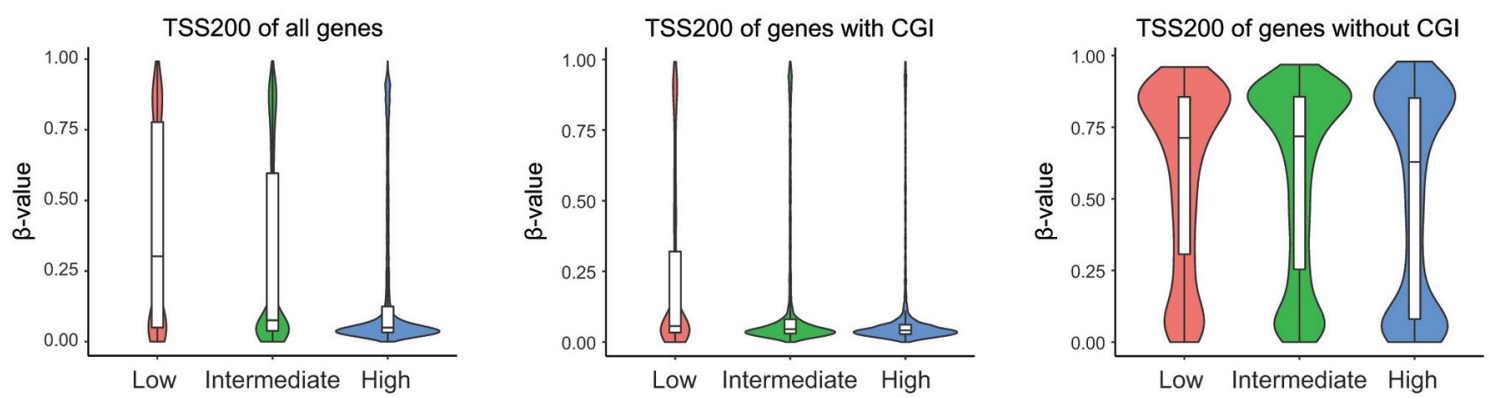

$\mathbf{F}$

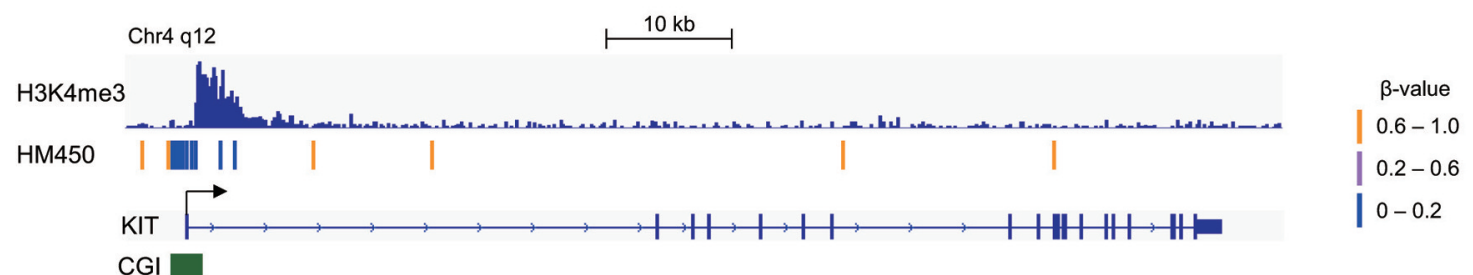

G

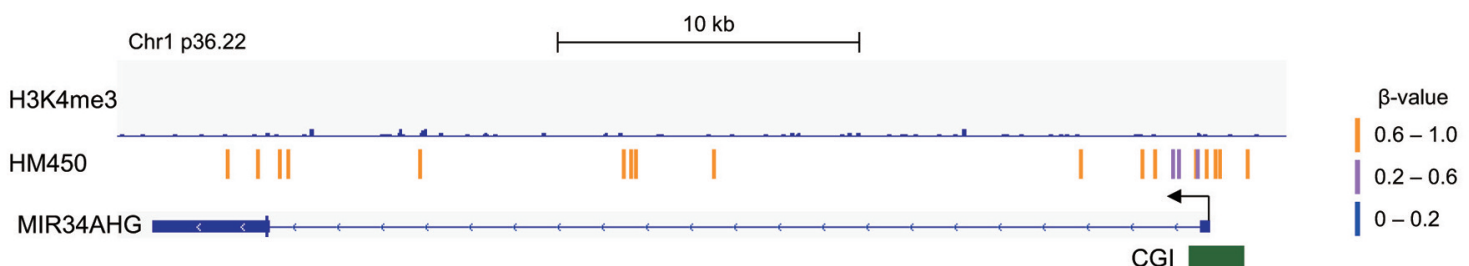

Figure 1. Overview of the H3K4me3 and DNA methylation states in GIST-T1 cells. (A) Workflow for this study. (B) Chromosomal locations of H3K4me3 peaks $(n=23,462)$ in GIST-T1 cells. (C) Metagene plots (upper) and heatmaps (lower) showing levels of H3K4me 3 around transcription

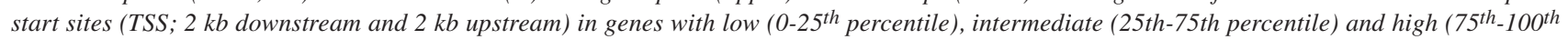
percentile) microarray signal intensities. (D) Density plots showing signals ( $\beta$-values) from Infinium HumanMethylation450 (HM450) probes located within the indicated chromosomal regions. (E) Levels of DNA methylation within the TSS200 regions of genes with the indicated microarray signal intensities. Results for all genes, genes with $C p G$ island $(C G I)$ and genes without $C G I$ are shown. $(F, G)$ Representative results of transcriptionally active $(F)$ and epigenetically silenced genes $(G)$. Levels of H3K4me3 and DNA methylation (HM450) are shown at the top. 
respective groups. The metagene plots and heatmaps in Figure $1 \mathrm{C}$ show that gene expression levels were tightly correlated with enrichment of $\mathrm{H} 3 \mathrm{~K} 4 \mathrm{me} 3$ at TSS regions.

We then used an Infinium HumanMethylation450 (HM450) BeadChip to analyze the DNA methylome in GIST-T1 cells. Density plot analyses revealed that the majority of the CpG sites from the TSS to the $1^{\text {st }}$ exon region and $\mathrm{CpG}$ islands were unmethylated, whereas they were largely methylated in the gene bodies and intergenic regions (Figure 1D). To assess the association between DNA methylation and gene expression, we selected probe sets of the BeadChip located within 200 bp upstream of TSSs (TSS200) and calculated the average methylation levels of the respective genes. We then examined the association of methylation levels of genes with their respective expression levels and found an inverse association between DNA methylation and gene expression (Figure 1E). Similar results were obtained when genes were categorized according to the presence or absence of CpG islands in their TSS regions. Most genes with $\mathrm{CpG}$ islands were unmethylated, while a small subset of genes with low expression exhibited elevated methylation levels (Figure 1E). Genes without $\mathrm{CpG}$ islands generally exhibited much higher levels of methylation than those with $\mathrm{CpG}$ islands, though a moderate inverse association between methylation and expression was still observed. Representative examples of epigenetically active and silent genes are shown in Figure 1F and G. A CpG island located at the TSS of the KIT gene was unmethylated, and this region was enriched with $\mathrm{H} 3 \mathrm{~K} 4 \mathrm{me} 3$ (Figure 1F). By contrast, a host gene encoding miR-34a (MIR34AHG) was epigenetically silenced in association with $\mathrm{CpG}$ island hypermethylation and a lack of H3K4me3 (5) (Figure 1G).

Effects of epigenetic inhibitors on gene expression in GIST cells. We next tested the effect of epigenetic inhibitors on GIST cells. Infinium assays revealed a series of genes hypermethylated at their TSS regions. With a stringent criterion (average $\beta$-value at TSS200 $>0.8$ ), 604 genes with $\mathrm{CpG}$ islands and 1,732 genes without $\mathrm{CpG}$ islands were defined as hypermethylated in GIST-T1 cells. Treatment with the DNMT inhibitor 5-aza-dC up-regulated expression of these genes, which confirmed the involvement of DNA methylation in gene repression (Figure 2A). When we applied a lower cutoff ( $\beta$-value $>0.6), 883$ genes with and 2,602 genes without $\mathrm{CpG}$ islands were found to be methylated, and their expression levels were also elevated by 5 -aza-dC treatment (data not shown). To further clarify the effect of drug treatment, we performed a pathway analysis of the genes up-regulated by 5-aza-dC in GIST-T1 cells and found significant enrichment of genes associated with interferon signaling (Figure 2B). We also observed that a combination of 5-aza-dC plus the histone deacetylase inhibitor 4-PBA led to stronger induction of genes related to interferon signaling than did 5-aza dC alone (Figure 2C-E). Gene Set Enrichment Analysis (GSEA) suggested that 5-aza$\mathrm{dC}+4-\mathrm{PBA}(\mathrm{AP})$ significantly activated both interferon- $\alpha / \beta$ and $-\gamma$ signaling in GIST cells (Figure 2F).

Effects of epigenetic inhibitors on histone methylation in GIST cells. To further clarify the effect of the epigenetic inhibitors, we carried out a ChIP-seq analysis of H3K4me3 in GIST-T1 cells treated with AP. We found that AP treatment significantly up-regulated the levels of $\mathrm{H} 3 \mathrm{~K} 4 \mathrm{me} 3$ in TSS regions, suggesting that a large number of epigenetically repressed genes were reactivated by the treatment (Figure 3A). A representative example of an epigenetically silenced gene is shown in Figure 3B. A $\mathrm{CpG}$ island in CAVI was hypermethylated in GIST-T1 cells, and the level of H3K4me3 was significantly up-regulated by AP (Figure 3B). The ChIPseq analysis revealed 13,451 peaks newly acquired with AP treatment (Figure 3C). Chromosomal locations of the peaks in GIST-T1 cells and those newly acquired with the treatment are summarized in Figure 3D and E. Most of the peaks were detected in promoter regions, and elevated levels of $\mathrm{H} 3 \mathrm{~K} 4 \mathrm{me} 3$ were confirmed in multiple genes up-regulated by AP (Figure $3 \mathrm{~F})$. Moreover, it is noteworthy that the newly acquired peaks were also frequently found within introns $(28.9 \%)$ and intergenic regions (18.7\%) (Figure 3E). Annotation of the peaks using HOMER revealed that substantial fractions of the intronic and intergenic peaks were located within retrotransposons, including short interspersed nuclear elements (SINEs), long interspersed nuclear elements (LINEs), and long terminal repeat (LTR) retrotransposons (Figure 3G). Representative examples of elevated $\mathrm{H} 3 \mathrm{~K} 4 \mathrm{me} 3$ levels in retrotransposon regions are shown in Figure $3 \mathrm{H}$. These results suggest that treatment with a DNMT inhibitor and an HDAC inhibitor restored expression of a number of epigenetically silenced genes as well as retrotransposons in GIST cells.

Screening for epigenetically silenced lncRNA genes in GIST. The results summarized above suggest that our transcriptome and epigenome data may be useful resources for identifying novel GIST-related genes. We therefore screened for epigenetically silenced lncRNA genes in GIST-T1 cells. Using the microarray data, we identified 28 lncRNAs that were significantly up-regulated ( $>2$-fold, $p<0.05$ ) by AP (Figure 4A and $\mathrm{B}$ ). Among them, 13 lncRNA genes contained $\mathrm{CpG}$ islands in their TSS regions. Using the ChIPseq data, we found that AP induced up-regulation of H3K4me3 in the TSS regions of five lncRNA genes (MEG3, NEAT1, GUSBP1, LOC100288911 and lnc-TMEM234-1; Figure 4A and C). The DNA methylation levels determined at the respective $\mathrm{CpG}$ sites using Infinium assays are summarized in Figure 4D. High levels of methylation were observed at CpG sites located proximal to TSSs of MEG3 and NEAT1 in GIST-T1 cells. By contrast, the levels of DNA 
A

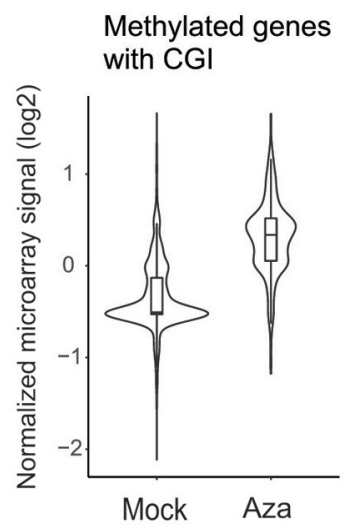

C

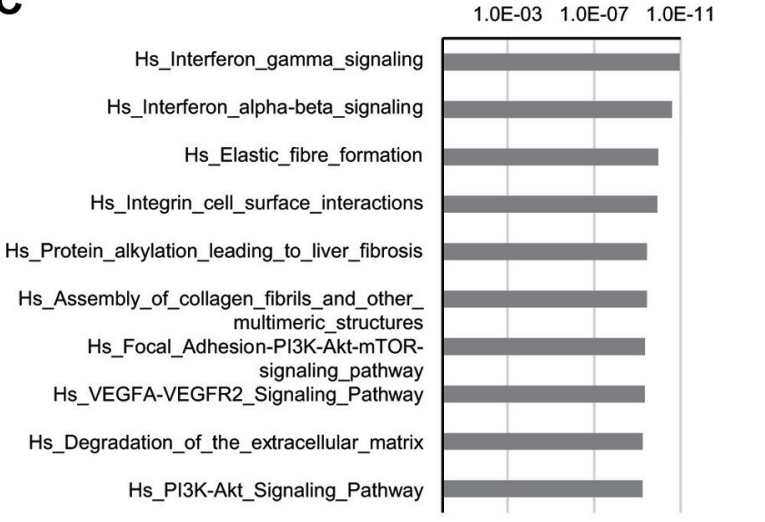

Methylated genes without CGI

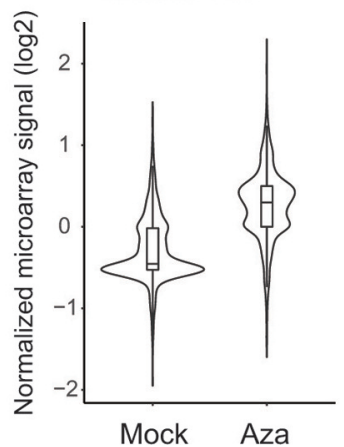

$\mathbf{F}$
B

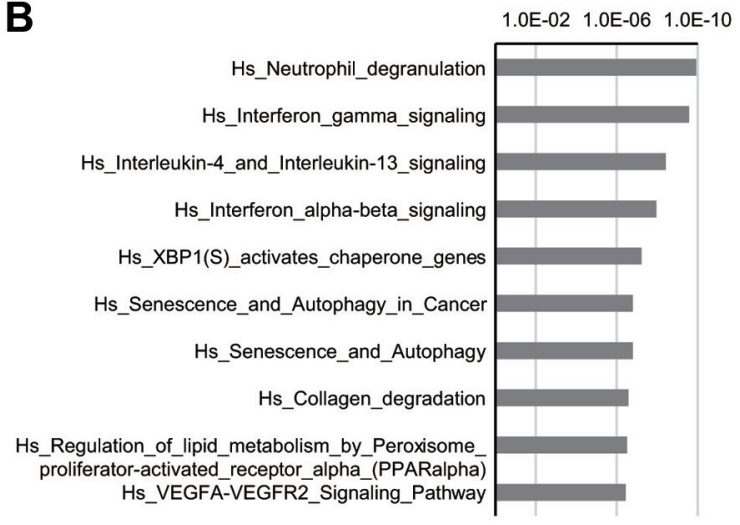

D

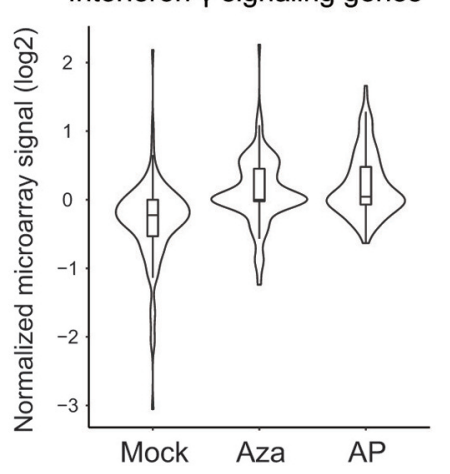

Interferon $\alpha / \beta$ signalinggenes

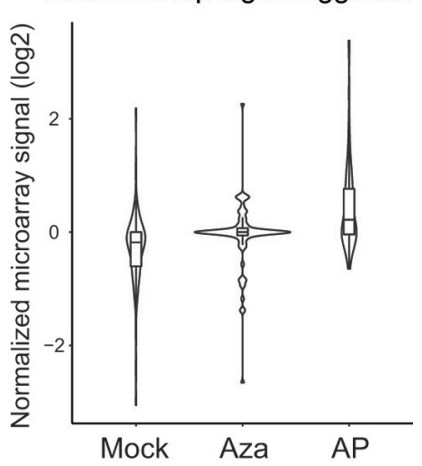

E

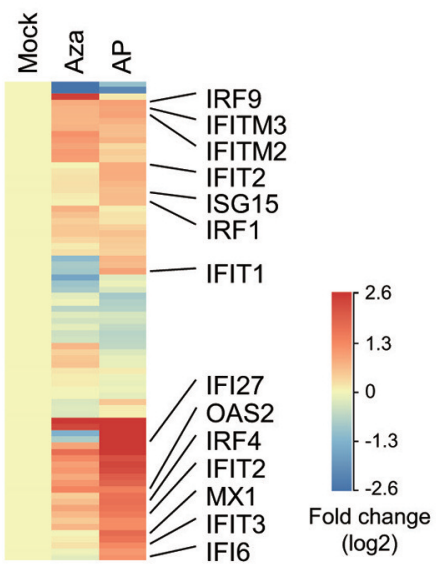

Interferon y signaling genes

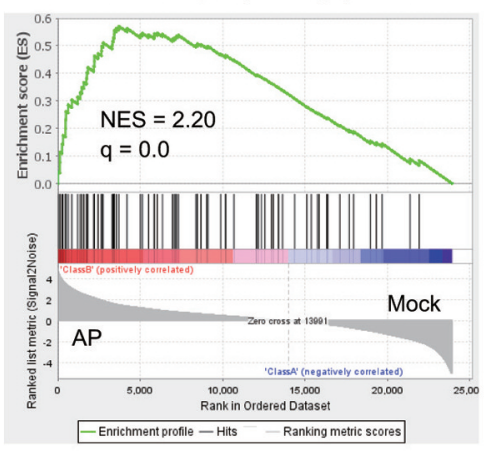

Interferon $\alpha / \beta$ signaling genes

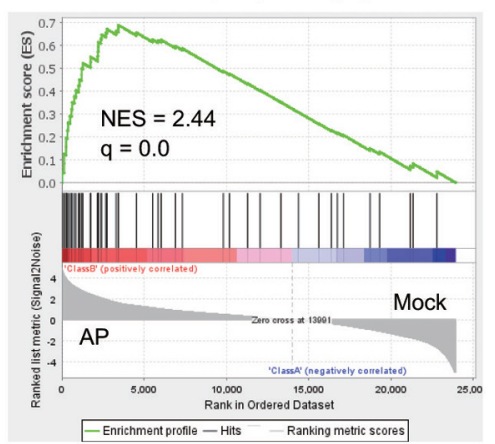

Figure 2. Effects of epigenetic inhibitors on gene expression in GIST-T1 cells. (A) Microarray results showing expression levels of genes with DNA methylation in GIST-T1 cells treated with mock or 5-aza-dC $(A z a) .(B, C)$ Pathway analyses of genes up-regulated by 5-aza-dC (B) or 5-aza-dC plus 4-PBA $(A P ; C)$. (D) Microarray results for genes associated with interferon- $\gamma$ (left) and interferon $\alpha / \beta$ (right) signaling. (E) Heatmap showing microarray results for interferon- $\alpha / \beta$ signaling genes in GIST-T1 cells treated as indicated. (F) GSEA of the indicated gene sets carried out using microarray data from cells treated with mock or AP.

methylation in other lncRNA genes were relatively limited (Figure 4D). To assess the clinical relevance of the methylation of these genes, we carried out Infinium assays with a series of 44 primary GISTs. We found that MEG3 was significantly methylated in the primary GISTs, while other lncRNA genes showed moderate methylation (Figure 4D).

We therefore selected MEG3 for further analysis. Detailed bisulfite sequencing analysis confirmed that the 
A

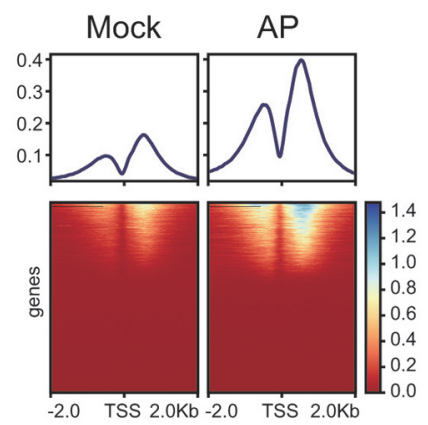

C

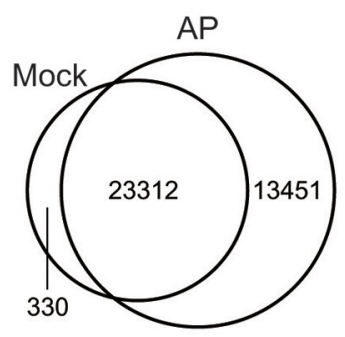

B

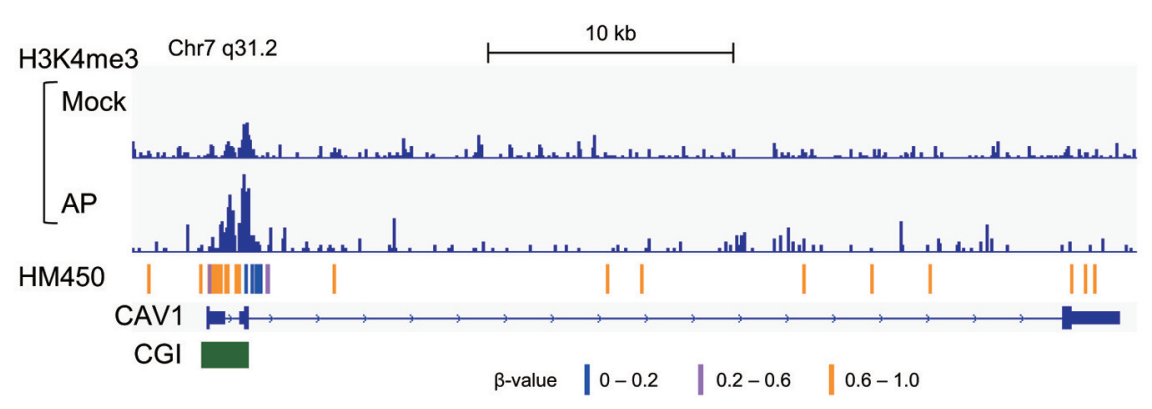

D
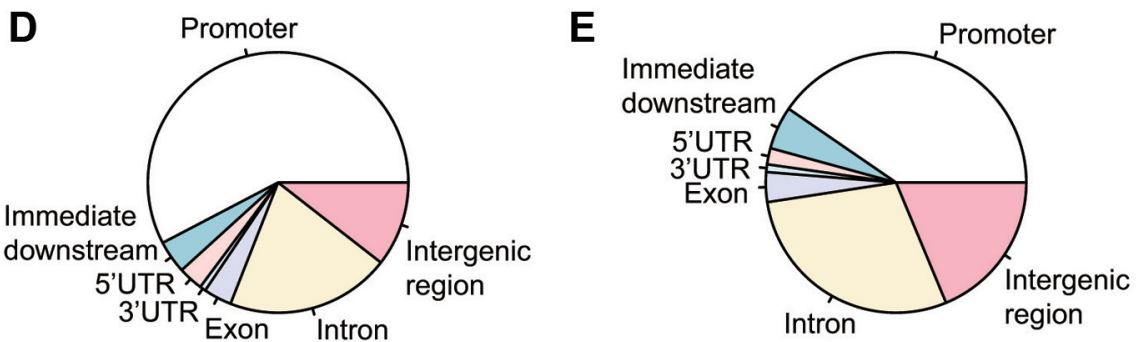

$\mathbf{F}$

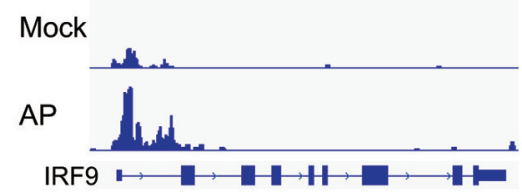

Chr10 q23.31

Mock

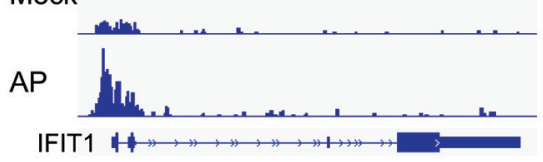

Chr1 p36.11

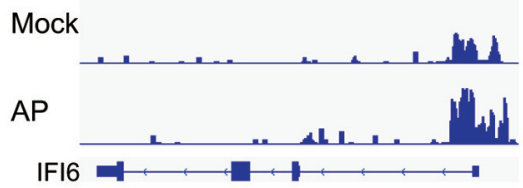

G Intron

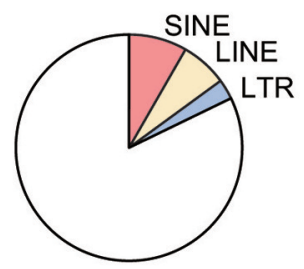

H

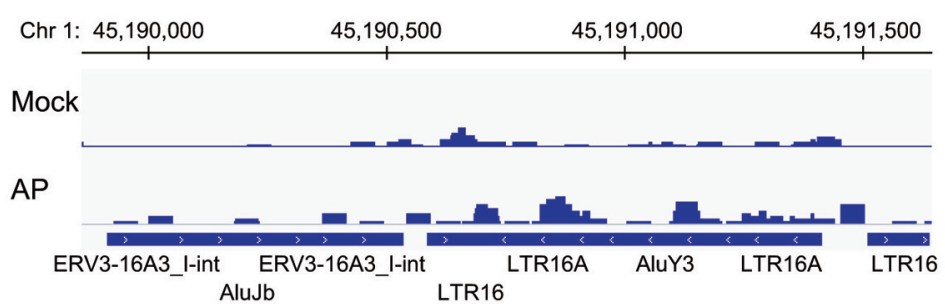

Intergenic region
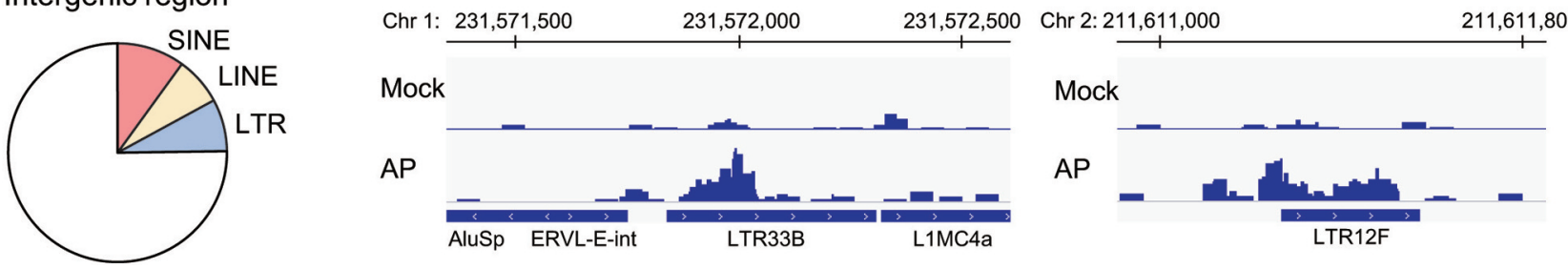

Figure 3. Effects of epigenetic inhibitors on H3K4me3 in GIST-T1 cells. (A) Metagene plot and heatmap showing H3K4me 3 levels around the transcription start sites (TSS; $2 \mathrm{~kb}$ downstream and $2 \mathrm{~kb}$ upstream) of all genes in GIST-T1 cells treated with mock or 5-aza-dC plus 4-PBA (AP). (B) Representative example of a gene (CAV1) activated by AP. Levels of H3K4me3 and HumanMethylation450 (HM450) signals are shown above, and the location of a CpG island (CGI) is shown below. (C) Venn diagram showing the numbers of H3K4me3 peaks in GIST-T1 cells treated as indicated. (D, E) Chromosomal locations of H3K4me3 peaks in GIST-T1 cells (D) and the locations of H3K4me3 peaks induced by AP (E). (F) H3K4me 3 levels in representative interferon signaling genes. $(G)$ Locations of AP-induced intronic and intergenic H3K4me 3 peaks within the indicated retrotransposon regions. $(H)$ Representative examples of retrotransposon regions in which H3K4me3 levels were elevated by AP treatment. 
A

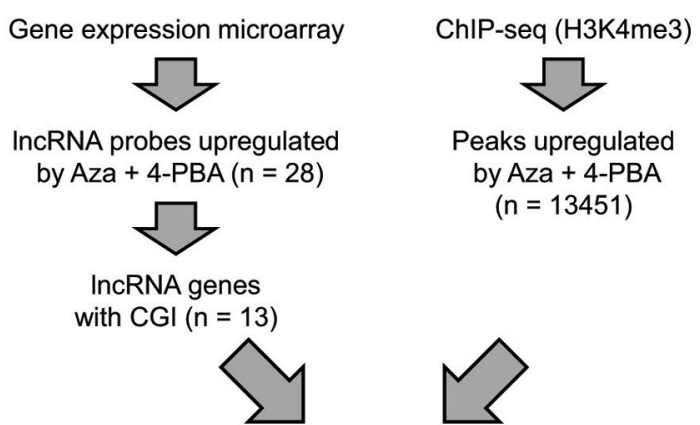

Candidate IncRNA genes $(n=5)$

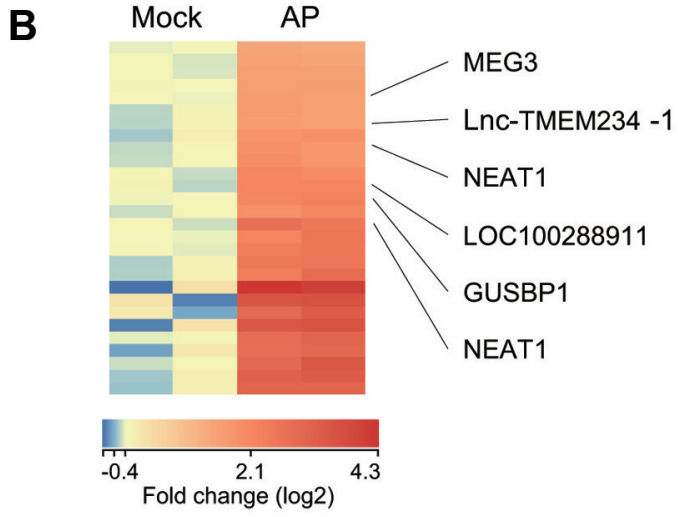

D

MEG3

GIST-T1

GSE34387

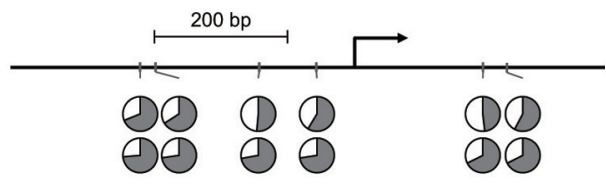

NEAT1

$\begin{array}{lll}\text { GIST-T1 } & \text { GSE34387 } & \text { (1) }\end{array}$

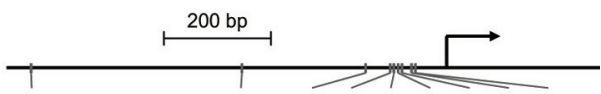

Mock chr11 q13.1

NEAT1 CGI

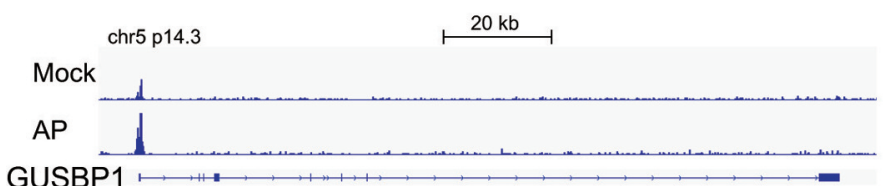

CGI I
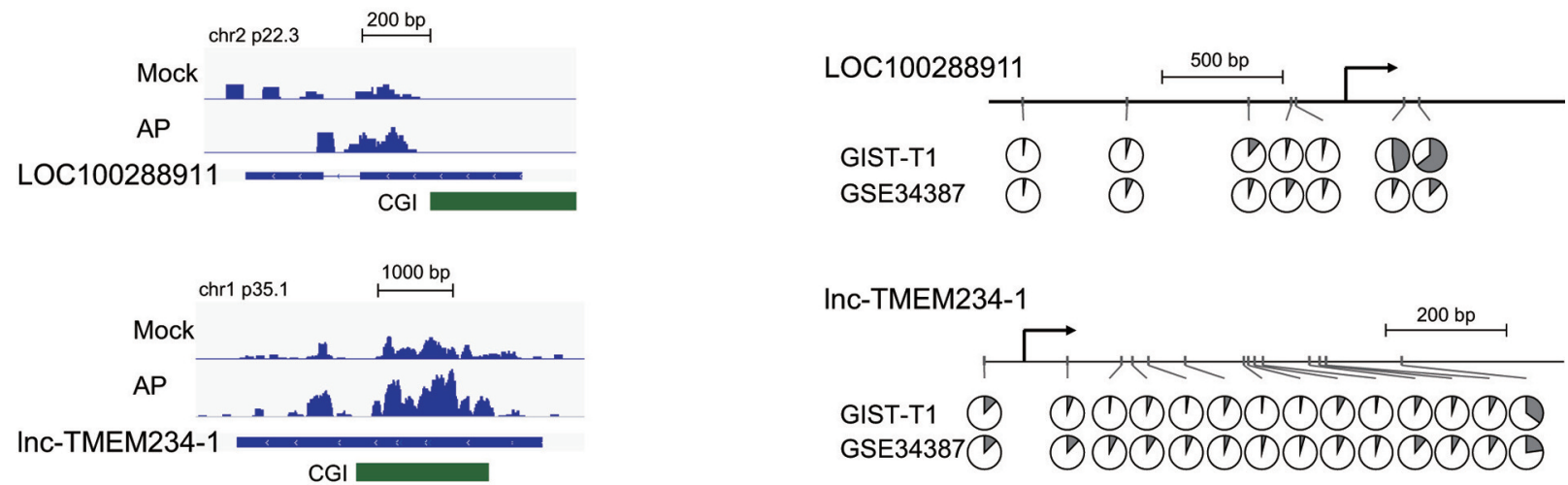

Figure 4. Identification of epigenetically silenced lncRNA genes in gastrointestinal stromal tumors (GISTs). (A) Workflow to identify epigenetically silenced lncRNA genes. (B) Heatmap showing microarray results for 28 selected lncRNAs in GIST-T1 cells treated with mock or 5-aza-dC plus 4$P B A(A P) .(C) H 3 K 4 m e 3$ levels in five selected lncRNA genes in cells treated as indicated. Locations of the CpG islands (CGI) are shown below. (D) DNA methylation levels of the five lncRNA genes. Circle graphs representing the methylation levels of respective CpG sites located around the transcription start sites of IncRNA genes in GIST-T1 cells. Results in primary GISTs (GSE34387, $n=44$ ) are also shown. 

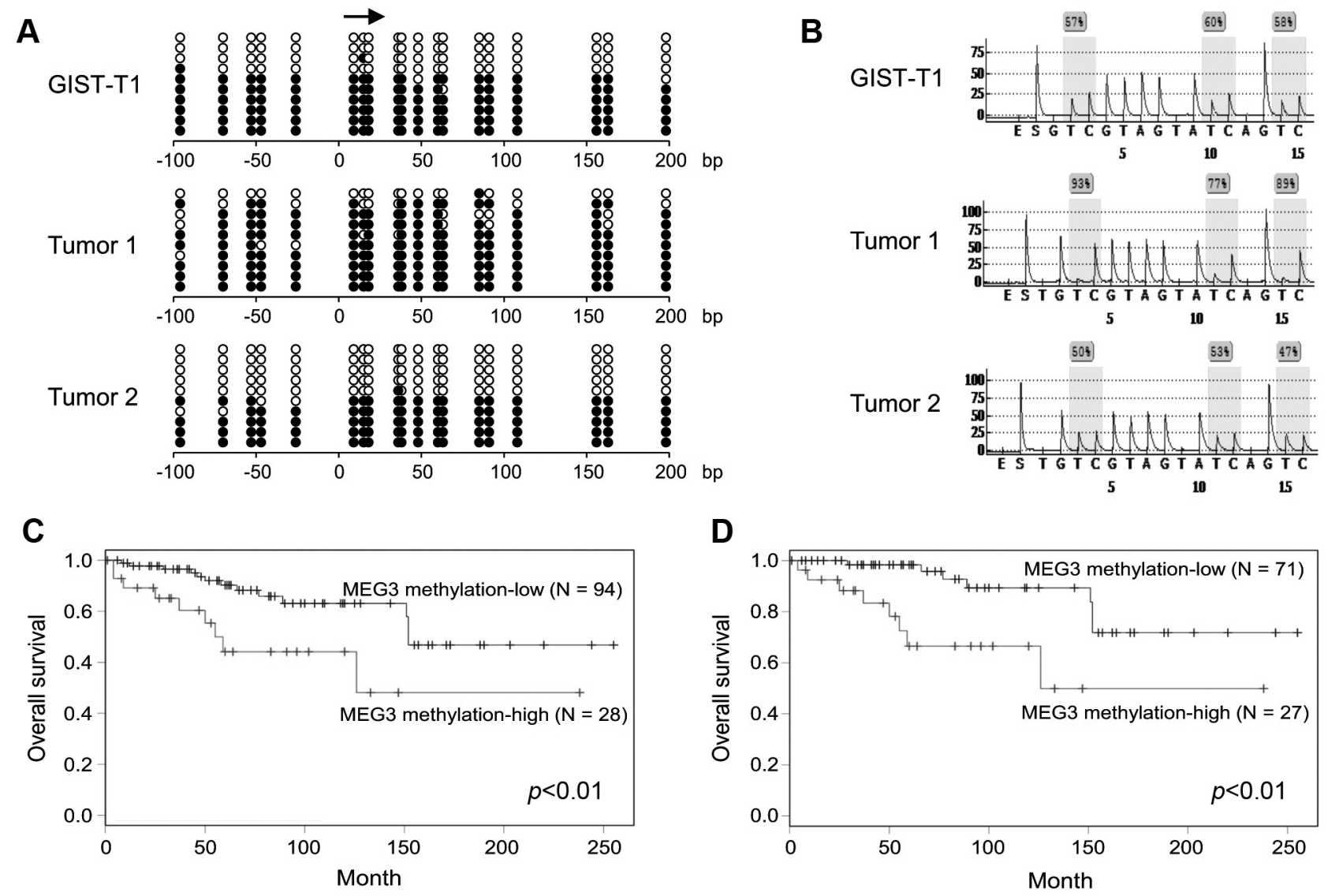

Figure 5. Analysis of MEG3 methylation in gastrointestinal stromal tumors (GISTs). (A, B) Results of bisulfite sequencing of MEG3 in GIST T1 cells and primary tumors. The region analyzed by bisulfite pyrosequencing is indicated by an arrow on the top. (B) Representative results of bisulfite pyrosequencing of MEG3 in GIST T1 cells and primary tumors. $(C, D)$ Kaplan-Meier curves showing the effects of MEG3 methylation on survival of patients with GIST. C) All tumor locations; D) stomach.

CpG island in MEG3 was densely methylated in both GIST$\mathrm{T} 1$ cells and primary tumors (Figure $5 \mathrm{~A}$ ). We next performed bisulfite pyrosequencing of $M E G 3$ in a series of 131 primary GISTs and assessed its correlation with the clinicopathological characteristics of the patients (Figure 5, Table II). We found that levels of MEG3 methylation were significantly higher in GISTs located in the stomach than than those from other origins including small intestine and colon (Table II). Further investigation of MEG3 methylation in gastric GISTs revealed that the higher $M E G 3$ methylation was associated with postoperative recurrence (Table III). By contrast, MEG3 methylation was not associated with any clinicopathological features tested in GISTs from other origins (Table IV). Kaplan-Meier curve analysis showed that higher levels (>87\%) of MEG3 methylation were associated with poorer overall survival of patients with GISTs, irrespective of the tumor location (Figure 5C and D).

\section{Discussion}

In this study, we re-confirmed that epigenetic modifications tightly correlate with genome-wide transcriptional regulation in GIST cells. Our ChIP-seq analysis showed that H3K4me3 was significantly enriched within active TSS regions in both protein-coding and noncoding genes. By contrast, DNA methylation in TSS regions negatively correlates with gene transcription. In particular, most TSS regions containing $\mathrm{CpG}$ islands were depleted of DNA methylation, while a small subset of $\mathrm{CpG}$ islands exhibited hypermethylation in GIST cells. Aberrant hypermethylation of $\mathrm{CpG}$ islands was associated with tumor progression, and approximately 5-10\% of $\mathrm{CpG}$ islands reportedly gain aberrant DNA methylation in various types of human cancer (18). We also found that in GIST cells, the levels of DNA methylation were relatively high in TSS regions without CpG islands and in gene body regions and intergenic regions. It is well documented that 
Table II. Correlation between MEG3 methylation levels and the clinicopathological features of GISTs.

\begin{tabular}{lccc}
\hline & $\mathrm{N}$ & $\begin{array}{c}\text { MEG3 methylation (\%) } \\
(\text { mean } \pm 95 \% \mathrm{CI})\end{array}$ & $p$-Value \\
& & & \\
\hline Age & 62 & $65.3 \pm 24.8$ & 0.80 \\
$\quad>65$ & 60 & $64.1 \pm 28.2$ & \\
$\quad \leq 65$ & & & \\
Gender & 64 & $62.5 \pm 27.8$ & 0.36 \\
$\quad$ Female & 57 & $66.9 \pm 25.0$ & \\
$\quad$ Male & & & \\
$\quad$ Tumor location & 98 & $68.6 \pm 25.3$ & $<0.01$ \\
$\quad$ Stomach & 23 & $47.2 \pm 24.9$ & \\
$\quad$ Other & & & \\
Recurrence & 21 & $65.6 \pm 32.4$ & 0.85 \\
$\quad+$ & 100 & $64.4 \pm 25.3$ & \\
$\quad$ & & & \\
$\quad$ Risk classification (Fletcher) & 34 & $63.8 \pm 27.7$ & 0.96 \\
$\quad$ High & 32 & $65.8 \pm 27.3$ & \\
$\quad$ Intermediate & 53 & $64.6 \pm 25.0$ & \\
$\quad$ Low or very low & &
\end{tabular}

Table III. Correlation between MEG3 methylation levels and the clinicopathological features of gastric GISTs.

\section{$\mathrm{N}$ MEG3 methylation (\%) $\quad$-Value} $($ mean $\pm 95 \% \mathrm{CI})$

\begin{tabular}{lccc}
\hline Age & & & \\
$>65$ & 50 & $67 \pm 28.2$ & 0.51 \\
$\leq 65$ & 48 & $70.4 \pm 22.1$ & \\
Gender & & & \\
$\quad$ Female & 53 & $66.9 \pm 26.9$ & 0.52 \\
$\quad$ Male & 44 & $70.3 \pm 23.6$ & \\
Recurrence & & & \\
$\quad+$ & 13 & $85 \pm 18.2$ & $<0.05$ \\
$\quad$ & 85 & $66.1 \pm 25.4$ & \\
Risk grade & & & \\
$\quad$ High & 23 & $74.4 \pm 21.0$ & 0.41 \\
$\quad$ Intermediate & 25 & $68.8 \pm 26.9$ & \\
Low or very low & 47 & $65.9 \pm 25.6$ & \\
\hline
\end{tabular}

DNA methylation within gene bodies is normally maintained at a high level, and it correlates positively with gene expression through inhibition of abnormal promoter activity or regulation of transcribed gene splicing (19).

When we treated GIST cells with DNMT and HDAC inhibitors, we found that they restored expression of a number of epigenetically silenced genes. To our knowledge, this is the first report showing that epigenetic inhibitors are able to activate interferon signaling within GIST cells, while several earlier studies demonstrated that 5-aza-dC treatment leads to up-regulation of genes related to immune responses and interferon signaling in cancer cells $(20,21)$. Recently,
Table IV. Correlation between MEG3 methylation levels and the clinicopathological features of non-gastric GISTs.

\section{n $\quad$ MEG3 methylation (\%) $p$-Value} $($ mean $\pm 95 \% \mathrm{CI})$

\begin{tabular}{lrcc}
\hline Age & & & \\
$\quad>65$ & 9 & $47.8 \pm 26.7$ & 0.89 \\
$\leq 65$ & 14 & $64.1 \pm 28.2$ & \\
Gender & & & \\
$\quad$ Female & 11 & $40.8 \pm 22.0$ & 0.25 \\
$\quad$ Male & 12 & $53.1 \pm 26.9$ & \\
Tumor location & & & \\
$\quad$ Esophagus & 4 & $42.9 \pm 30.8$ & 0.48 \\
$\quad$ Small intestine & 16 & $44.9 \pm 24.4$ & \\
$\quad$ Colon & 2 & $56.8 \pm 14.9$ & \\
$\quad$ Omentum & 1 & 83.2 & \\
Recurrence & & & \\
$\quad+$ & 8 & $54.3 \pm 23.0$ & 0.06 \\
$\quad$ & 15 & $34.0 \pm 24.1$ & \\
Risk classification (Fletcher) & & & \\
$\quad$ High & 10 & $37.5 \pm 25.4$ & 0.27 \\
Intermediate & 7 & 54.827 .9 & \\
$\quad$ Low or very low & 6 & $54.6 \pm 17.3$ & \\
\hline
\end{tabular}

the mechanism underlying activation of interferon signaling by inhibition of DNA methylation was clarified. That mechanism, viral mimicry, is triggered by re-expression of endogenous retroviruses (ERVs) and production of doublestranded RNAs that lead to activation of type I and/or III interferon responses via activation of the MDA5/MAVS RNA recognition pathway (22-24). In the present study, we found that treating GIST cells with epigenetic inhibitors upregulated $\mathrm{H} 3 \mathrm{~K} 4 \mathrm{me} 3$ levels at numerous retrotransposon regions. Retrotransposons are subdivided into two groups based on the presence or absence of long terminal repeats (LTRs), and LTR elements including ERVs and related elements account for approximately $8 \%$ of the human genome (25). Our results suggest that epigenetic treatment may modulate the immune environment within GISTs and potentially elicit antitumor effects in combination with immunotherapy.

LncRNAs are non-coding transcripts with a length of more than $200 \mathrm{nt}$ and are expressed uniquely in various differentiated cells or tumor types (26). Biological functions in which lncRNAs are reportedly involved include development, differentiation, apoptosis and tumorigenesis (27). We previously reported that HOTAIR expression is associated with high-risk GIST and poor prognoses in GIST patients (9). HOTAIR also reportedly regulates GIST progression by inducing hypermethylation and silencing PCDH10 (28). LncRNA CCDC26 knockdown reportedly induces imatinib resistance through regulation of c-KIT or IGF-1R expression $(29,30)$. These results suggest that 
lncRNAs may play pivotal roles in the pathogenesis of GISTs. In the present study, we applied our epigenome and transcriptome data to screen for lncRNAs epigenetically down-regulated in GISTs and identified five (MEG3, NEAT1, GUSBP1, LOC100288911, and lnc-TMEM234-1), among which $M E G 3$ was the most frequently hypermethylated in primary GISTs.

MEG3 is located within an imprinted gene cluster on chromosome 14q32.3 $(31,32)$. Its expression is regulated by two differentially methylated regions (DMRs): the intergenic DMR (IG-DMR) and the MEG3-DMR (33). Because deletion of the region containing the IG-DMR leads to loss of MEG3 expression, the IG-DMR is thought to regulate transcriptional activation of MEG3 (33). MEG3-DMR overlaps with $M E G 3$ promoter, and its hypermethylation has been observed in various malignancies, including meningioma, cervical cancer, gastric cancer, acute myeloid leukemia (AML), and myelodysplastic syndrome (34-37). In addition, epigenetic silencing of MEG3 via promoter hypermethylation has been reported in glioma, hepatocellular carcinoma, and epithelial ovarian cancer (38-40).

Multiple lines of evidence suggest that MEG3 acts as a tumor suppressor in various tumors. In AML cells, dysregulation of WT1 and TET2 leads to down-regulation of MEG3 and progression of leukemogenesis (41). In esophageal and prostate cancer, MEG3 inhibits cell growth and invasiveness by acting as a competing endogenous RNA (ceRNA) against miR-9 $(42,43)$. The role of MEG3 as a ceRNA has also been reported in prostate cancer (44). In hepatoma cells, MEG3 inhibits cell proliferation and induces apoptosis through interaction with $\mathrm{p} 53$ or down-regulation of ADH4 via competition with miR-664 $(45,46)$. It has also been reported that in epithelial ovarian cancer, MEG3 inhibits cell proliferation by interacting with ATG3 and inducing autophagy (47). Taken together with these findings, our observations suggest hypermethylation of MEG3 contributes to the pathogenesis GISTs and to poorer prognoses in GIST patients.

In summary, we performed an integrated analysis of the epigenome and transcriptome in GIST cells and confirmed the tight association between DNA methylation, histone modification and gene expression. We further demonstrated that treatment with an epigenetic inhibitor leads to activation of interferon signaling in GIST cells and that restoration of repetitive elements, including ERV genes, may be involved in interferon signaling. We also showed that our data could be a useful resource for identifying novel GIST-related genes.

\section{Conflicts of Interest}

All Authors have no conflicts of interest to declare in relation to this study.

\section{Authors' Contributions}

Conceived and designed the experiments: H. Suzuki, H. Nakase, T. Sugai. Performed the experiments: M. Toyota, T. Niinuma, K. Ishiguro, H. Aoki, T. Harada. Analyzed the data: T. Niinuma. E. Yamamoto, G. Sudo, A. Yoshido, M. Kai. Contributed materials/analysis tools: R. Maruyama, H. Nakase. Wrote the paper: T. Niinuma, H. Suzuki.

\section{Acknowledgements}

The Authors would like to thank Dr. William F. Goldman for editing the manuscript and Ms. Tomo Hatahira for technical assistance. This study was supported in part by a Grant-in-Aid for Young Investigators (B) from the Japan Society for Promotion of Science (JSPS KAKENHI 16K19352, T. Niinuma), a Grant-in-Aid for Scientific Research (B) from the Japan Society for Promotion of Science (JSPS KAKENHI 19H03518, H. Suzuki) the Takeda Science Foundation (2018, T. Niinuma), and the Jikeikai Tomoiki Foundation (T. Niinuma).

\section{References}

1 Joensuu H, Hohenberger P and Corless CL: Gastrointestinal stromal tumour. Lancet 382(9896): 973-983, 2013. PMID: 23623056. DOI: 10.1016/S0140-6736(13)60106-3

2 Killian JK, Kim SY, Miettinen M, Smith C, Merino M, Tsokos M, Quezado M, Smith WI Jr, Jahromi MS, Xekouki P, Szarek E, Walker RL, Lasota J, Raffeld M, Klotzle B, Wang Z, Jones L, Zhu Y, Wang Y, Waterfall JJ, O’Sullivan MJ, Bibikova M, Pacak K, Stratakis C, Janeway KA, Schiffman JD, Fan JB, Helman L and Meltzer PS: Succinate dehydrogenase mutation underlies global epigenomic divergence in gastrointestinal stromal tumor. Cancer Discov 3(6): 648-657, 2013. PMID: 23550148. DOI: 10.1158/2159-8290.CD-13-0092

3 Flavahan WA, Drier Y, Johnstone SE, Hemming ML, Tarjan DR, Hegazi E, Shareef SJ, Javed NM, Raut CP, Eschle BK, Gokhale PC, Hornick JL, Sicinska ET, Demetri GD and Bernstein BE: Altered chromosomal topology drives oncogenic programs in SDH-deficient GISTs. Nature 575(7781): 229-233, 2019. PMID: 31666694. DOI: $10.1038 / \mathrm{s} 41586-019-1668-3$

4 Okamoto Y, Sawaki A, Ito S, Nishida T, Takahashi T, Toyota M, Suzuki H, Shinomura Y, Takeuchi I, Shinjo K, An B, Ito H, Yamao K, Fujii M, Murakami H, Osada H, Kataoka H, Joh T, Sekido Y and Kondo Y: Aberrant DNA methylation associated with aggressiveness of gastrointestinal stromal tumour. Gut 61(3): 392-401, 2012. PMID: 21708825. DOI: 10.1136/gut.2011.241034

5 Isosaka M, Niinuma T, Nojima M, Kai M, Yamamoto E, Maruyama R, Nobuoka T, Nishida T, Kanda T, Taguchi T, Hasegawa T, Tokino T, Hirata K, Suzuki H and Shinomura Y: A screen for epigenetically silenced microRNA genes in gastrointestinal stromal tumors. PLoS One 10(7): e0133754, 2015. PMID: 26214687. DOI: 10.1371/journal.pone.0133754

6 Igarashi S, Suzuki H, Niinuma T, Shimizu H, Nojima M, Iwaki H, Nobuoka T, Nishida T, Miyazaki Y, Takamaru H, Yamamoto E, Yamamoto H, Tokino T, Hasegawa T, Hirata K, Imai K, Toyota M and Shinomura Y: A novel correlation between LINE1 hypomethylation and the malignancy of gastrointestinal stromal tumors. Clin Cancer Res 16(21): 5114-5123, 2010. PMID: 20978145. DOI: 10.1158/1078-0432.CCR-10-0581 
7 Barski A, Cuddapah S, Cui K, Roh TY, Schones DE, Wang Z, Wei G, Chepelev I and Zhao K: High-resolution profiling of histone methylations in the human genome. Cell 129(4): 823837, 2007. PMID: 17512414. DOI: 10.1016/j.cell.2007.05.009

8 Pengelly AR, Copur Ö, Jäckle H, Herzig A and Müller J: A histone mutant reproduces the phenotype caused by loss of histone-modifying factor Polycomb. Science 339(6120): 698699, 2013. PMID: 23393264. DOI: 10.1126/science.1231382

9 Niinuma T, Suzuki H, Nojima M, Nosho K, Yamamoto H, Takamaru H, Yamamoto E, Maruyama R, Nobuoka T, Miyazaki Y, Nishida T, Bamba T, Kanda T, Ajioka Y, Taguchi T, Okahara S, Takahashi H, Nishida Y, Hosokawa M, Hasegawa T, Tokino T, Hirata $\mathrm{K}$, Imai $\mathrm{K}$, Toyota $\mathrm{M}$ and Shinomura Y: Upregulation of miR-196a and HOTAIR drive malignant character in gastrointestinal stromal tumors. Cancer Res 72(5): 1126-1136, 2012. PMID: 22258453. DOI: 10.1158/0008-5472.CAN-11-1803

10 Taguchi T, Sonobe H, Toyonaga S, Yamasaki I, Shuin T, Takano A, Araki K, Akimaru K and Yuri K: Conventional and molecular cytogenetic characterization of a new human cell line, GIST-T1, established from gastrointestinal stromal tumor. Lab Invest 82(5): 663-665, 2002. PMID: 12004007. DOI: 10.1038/labinvest.3780461

11 Fletcher CD, Berman JJ, Corless C, Gorstein F, Lasota J, Longley BJ, Miettinen M, O'Leary TJ, Remotti H, Rubin BP, Shmookler B, Sobin LH and Weiss SW: Diagnosis of gastrointestinal stromal tumors: A consensus approach. Hum Pathol 33(5): 459-465, 2002. PMID: 12094370. DOI: 10.1053/hupa.2002.123545

12 Suzuki H, Takatsuka S, Akashi H, Yamamoto E, Nojima M, Maruyama R, Kai M, Yamano HO, Sasaki Y, Tokino T, Shinomura Y, Imai K and Toyota M: Genome-wide profiling of chromatin signatures reveals epigenetic regulation of MicroRNA genes in colorectal cancer. Cancer Res 71(17): 5646-5658, 2011. PMID: 21734013. DOI: 10.1158/0008-5472.CAN-11-1076

13 Zhang Y, Liu T, Meyer CA, Eeckhoute J, Johnson DS, Bernstein BE, Nusbaum C, Myers RM, Brown M, Li W and Liu XS: Model-based analysis of ChIP-Seq (MACS). Genome Biol 9(9): R137, 2008. PMID: 18798982. DOI: 10.1186/gb-2008-9-9-r137

14 Zhu LJ, Gazin C, Lawson ND, Pagès H, Lin SM, Lapointe DS and Green MR: ChIPpeakAnno: a Bioconductor package to annotate ChIP-seq and ChIP-chip data. BMC Bioinformatics 11: 237, 2010. PMID: 20459804. DOI: 10.1186/1471-2105-11-237

15 Robinson JT, Thorvaldsdóttir H, Winckler W, Guttman M, Lander ES, Getz G and Mesirov JP: Integrative genomics viewer. Nat Biotechnol 29(1): 24-26, 2011. PMID: 21221095. DOI: $10.1038 /$ nbt.1754

16 Niinuma T, Kitajima H, Kai M, Yamamoto E, Yorozu A, Ishiguro K, Sasaki H, Sudo G, Toyota M, Hatahira T, Maruyama R, Tokino T, Nakase H, Sugai T and Suzuki H: UHRF1 depletion and HDAC inhibition reactivate epigenetically silenced genes in colorectal cancer cells. Clin Epigenetics 11(1): 70, 2019. PMID: 31064417. DOI: 10.1186/s13148-019-0668-3

17 Kanda Y: Investigation of the freely available easy-to-use software 'EZR' for medical statistics. Bone Marrow Transplant 48(3): 452458, 2013. PMID: 23208313. DOI: 10.1038/bmt.2012.244

18 Baylin SB and Jones PA: A decade of exploring the cancer epigenome - biological and translational implications. Nat Rev Cancer 11(10): 726-734, 2011. PMID: 21941284. DOI: $10.1038 / \mathrm{nrc} 3130$

19 Yang X, Han H, De Carvalho DD, Lay FD, Jones PA and Liang G: Gene body methylation can alter gene expression and is a therapeutic target in cancer. Cancer Cell 26(4): 577-590, 2014. PMID: 25263941. DOI: 10.1016/j.ccr.2014.07.028

20 Missiaglia E, Donadelli M, Palmieri M, Crnogorac-Jurcevic T, Scarpa A and Lemoine NR: Growth delay of human pancreatic cancer cells by methylase inhibitor 5-aza-2'-deoxycytidine treatment is associated with activation of the interferon signalling pathway. Oncogene 24(1): 199-211, 2005. PMID: 15637593. DOI: $10.1038 /$ sj.onc. 1208018

21 Fujikane T, Nishikawa N, Toyota M, Suzuki H, Nojima M, Maruyama R, Ashida M, Ohe-Toyota M, Kai M, Nishidate T, Sasaki Y, Ohmura T, Hirata K and Tokino T: Genomic screening for genes upregulated by demethylation revealed novel targets of epigenetic silencing in breast cancer. Breast Cancer Res Treat 122(3): 699-710, 2010. PMID: 19859801. DOI: 10.1007/s10549009-0600-1

22 Chiappinelli KB, Strissel PL, Desrichard A, Li H, Henke C, Akman B, Hein A, Rote NS, Cope LM, Snyder A, Makarov V, Budhu S, Slamon DJ, Wolchok JD, Pardoll DM, Beckmann MW, Zahnow CA, Merghoub T, Chan TA, Baylin SB and Strick $\mathrm{R}$ : Inhibiting DNA methylation causes an interferon response in cancer via dsRNA including endogenous retroviruses. Cell 162(5): 974-986, 2015. PMID: 26317466. DOI: 10.1016/j.cell.2015.07.011

23 Jones PA, Ohtani H, Chakravarthy A and De Carvalho DD: Epigenetic therapy in immune-oncology. Nat Rev Cancer 19(3): 151-161, 2019. PMID: 30723290. DOI: 10.1038/s41568-0190109-9

24 Roulois D, Loo Yau H, Singhania R, Wang Y, Danesh A, Shen SY, Han H, Liang G, Jones PA, Pugh TJ, O'Brien C and De Carvalho DD: DNA-demethylating agents target colorectal cancer cells by inducing viral mimicry by endogenous transcripts. Cell 162(5): 961-973, 2015. PMID: 26317465. DOI: 10.1016/j.cell.2015.07.056

25 Cordaux R and Batzer MA: The impact of retrotransposons on human genome evolution. Nat Rev Genet 10(10): 691-703, 2009. PMID: 19763152. DOI: $10.1038 / \mathrm{nrg} 2640$

26 Iyer MK, Niknafs YS, Malik R, Singhal U, Sahu A, Hosono Y, Barrette TR, Prensner JR, Evans JR, Zhao S, Poliakov A, Cao X, Dhanasekaran SM, Wu YM, Robinson DR, Beer DG, Feng FY, Iyer HK and Chinnaiyan AM: The landscape of long noncoding RNAs in the human transcriptome. Nat Genet 47(3): 199-208, 2015. PMID: 25599403. DOI: $10.1038 / n g .3192$

27 Schmitt AM and Chang HY: Long noncoding RNAs in cancer pathways. Cancer Cell 29(4): 452-463, 2016. PMID: 27070700. DOI: $10.1016 /$ j.ccell.2016.03.010

28 Lee NK, Lee JH, Kim WK, Yun S, Youn YH, Park CH, Choi YY, Kim H and Lee SK: Promoter methylation of PCDH10 by HOTAIR regulates the progression of gastrointestinal stromal tumors. Oncotarget 7(46): 75307-75318, 2016. PMID: 27659532. DOI: $10.18632 /$ oncotarget.12171

29 Cao K, Li M, Miao J, Lu X, Kang X, Zhu H, Du S, Li X, Zhang Q, Guan W, Dong Y and Xia X: CCDC26 knockdown enhances resistance of gastrointestinal stromal tumor cells to imatinib by interacting with c-KIT. Am J Transl Res 10(1): 274-282, 2018. PMID: 29423012.

30 Yan J, Chen D, Chen X, Sun X, Dong Q, Hu C, Zhou F and Chen W: Downregulation of lncRNA CCDC26 contributes to imatinib resistance in human gastrointestinal stromal tumors through IGF1R upregulation. Braz J Med Biol Res 52(6): e8399, 2019. PMID: 31166382. DOI: 10.1590/1414-431x20198399 
31 Charlier C, Segers K, Wagenaar D, Karim L, Berghmans S, Jaillon O, Shay T, Weissenbach J, Cockett N, Gyapay G and Georges M: Human-ovine comparative sequencing of a $250-\mathrm{kb}$ imprinted domain encompassing the callipyge (clpg) locus and identification of six imprinted transcripts: DLK1, DAT, GTL2, PEG11, antiPEG11, and MEG8. Genome Res 11(5): 850-862, 2001. PMID: 11337479 . DOI: $10.1101 / \mathrm{gr} .172701$

32 Miyoshi N, Wagatsuma H, Wakana S, Shiroishi T, Nomura M, Aisaka K, Kohda T, Surani MA, Kaneko-Ishino T and Ishino F: Identification of an imprinted gene, Meg3/Gt12 and its human homologue MEG3, first mapped on mouse distal chromosome 12 and human chromosome 14q. Genes Cells 5(3): 211-220, 2000. PMID: 10759892. DOI: 10.1046/j.1365-2443.2000.00320.x

33 Kagami M, Sekita Y, Nishimura G, Irie M, Kato F, Okada M, Yamamori S, Kishimoto H, Nakayama M, Tanaka Y, Matsuoka K, Takahashi T, Noguchi M, Tanaka Y, Masumoto K, Utsunomiya T, Kouzan H, Komatsu Y, Ohashi H, Kurosawa K, Kosaki K, Ferguson-Smith AC, Ishino F and Ogata T: Deletions and epimutations affecting the human $14 \mathrm{q} 32.2$ imprinted region in individuals with paternal and maternal upd(14)-like phenotypes. Nat Genet 40(2): 237-242, 2008. PMID: 18176563. DOI: $10.1038 / \mathrm{ng} .2007 .56$

34 Benetatos L, Hatzimichael E, Dasoula A, Dranitsaris G, Tsiara S, Syrrou M, Georgiou I and Bourantas KL: CpG methylation analysis of the MEG3 and SNRPN imprinted genes in acute myeloid leukemia and myelodysplastic syndromes. Leuk Res 34(2): 148-153, 2010. PMID: 19595458. DOI: 10.1016/j.leukres.2009.06.019

35 Guo W, Dong Z, Liu S, Qiao Y, Kuang G, Guo Y, Shen S and Liang J: Promoter hypermethylation-mediated downregulation of miR-770 and its host gene MEG3, a long non-coding RNA, in the development of gastric cardia adenocarcinoma. Mol Carcinog 56(8): 1924-1934, 2017. PMID: 28345805. DOI: $10.1002 / \mathrm{mc} .22650$

36 Zhang J, Lin Z, Gao Y and Yao T: Downregulation of long noncoding RNA MEG3 is associated with poor prognosis and promoter hypermethylation in cervical cancer. J Exp Clin Cancer Res 36(1): 5, 2017. PMID: 28057015. DOI: 10.1186/s13046016-0472-2

37 Zhang X, Gejman R, Mahta A, Zhong Y, Rice KA, Zhou Y, Cheunsuchon P, Louis DN and Klibanski A: Maternally expressed gene 3, an imprinted noncoding RNA gene, is associated with meningioma pathogenesis and progression. Cancer Res 70(6): 2350-2358, 2010. PMID: 20179190. DOI: 10.1158/0008-5472.CAN-09-3885

38 Sheng X, Li J, Yang L, Chen Z, Zhao Q, Tan L, Zhou Y and Li $\mathrm{J}$ : Promoter hypermethylation influences the suppressive role of maternally expressed 3, a long non-coding RNA, in the development of epithelial ovarian cancer. Oncol Rep 32(1): 277285, 2014. PMID: 24859196. DOI: 10.3892/or.2014.3208
39 Anwar SL, Krech T, Hasemeier B, Schipper E, Schweitzer N, Vogel A, Kreipe $\mathrm{H}$ and Lehmann U: Loss of imprinting and allelic switching at the DLK1-MEG3 locus in human hepatocellular carcinoma. PLoS One 7(11): e49462, 2012. PMID: 23145177. DOI: 10.1371/journal.pone.0049462

40 Li J, Bian EB, He XJ, Ma CC, Zong G, Wang HL and Zhao B: Epigenetic repression of long non-coding RNA MEG3 mediated by DNMT1 represses the p53 pathway in gliomas. Int J Oncol 48(2): 723-733, 2016. PMID: 26676363. DOI: 10.3892/ijo.2015.3285

41 Yao H, Duan M, Lin L, Wu C, Fu X, Wang H, Guo L, Chen W, Huang L, Liu D, Rao R, Wang S and Ding Y: TET2 and MEG3 promoter methylation is associated with acute myeloid leukemia in a Hainan population. Oncotarget 8(11): 18337-18347, 2017. PMID: 28407691. DOI: 10.18632/oncotarget.15440

42 Dong Z, Zhang A, Liu S, Lu F, Guo Y, Zhang G, Xu F, Shi Y, Shen S, Liang J and Guo W: Aberrant methylation-mediated silencing of lncRNA MEG3 functions as a ceRNA in esophageal cancer. Mol Cancer Res 15(7): 800-810, 2017. PMID: 28539329. DOI: 10.1158/1541-7786.MCR-16-0385

43 Lyu Y, Lou J, Yang Y, Feng J, Hao Y, Huang S, Yin L, Xu J, Huang D, Ma B, Zou D, Wang Y, Zhang Y, Zhang B, Chen P, Yu K, Lam EW, Wang X, Liu Q, Yan J and Jin B: Dysfunction of the WT1-MEG3 signaling promotes AML leukemogenesis via p53-dependent and -independent pathways. Leukemia 31(12): 2543-2551, 2017. PMID: 28400619. DOI: 10.1038/leu.2017.116

44 Liu D, Yu X, Wang S, Dai E, Jiang L, Wang J, Yang Q, Yang F, Zhou $\mathrm{S}$ and Jiang $\mathrm{W}$ : The gain and loss of long noncoding RNA associated-competing endogenous RNAs in prostate cancer. Oncotarget 7(35): 57228-57238, 2016. PMID: 27528026. DOI: 10.18632 /oncotarget. 11128

45 He JH, Han ZP, Liu JM, Zhou JB, Zou MX, Lv YB, Li YG and Cao MR: Overexpression of long non-coding RNA MEG3 inhibits proliferation of hepatocellular carcinoma Huh7 cells via negative modulation of miRNA-664. J Cell Biochem 118(11): 3713-3721, 2017. PMID: 28374914. DOI: 10.1002/jcb.26018

46 Zhu J, Liu S, Ye F, Shen Y, Tie Y, Zhu J, Wei L, Jin Y, Fu H, $\mathrm{Wu} \mathrm{Y}$ and Zheng X: Long noncoding RNA MEG3 interacts with p53 protein and regulates partial p53 target genes in hepatoma cells. PLoS One 10(10): e0139790, 2015. PMID: 26444285. DOI: 10.1371/journal.pone.0139790

47 Xiu YL, Sun KX, Chen X, Chen S, Zhao Y, Guo QG and Zong ZH: Upregulation of the lncRNA Meg3 induces autophagy to inhibit tumorigenesis and progression of epithelial ovarian carcinoma by regulating activity of ATG3. Oncotarget 8(19): 31714-31725, 2017. PMID: 28423647. DOI: 10.18632/oncotarget.15955

Received April 29, 2021

Revised May 12, 2021

Accepted May 13, 2021 